\title{
Cecilia Grierson y las damas de la Beneficencia oficial en los orígenes del Consejo Nacional de Mujeres de Argentina (1887-1906)
}

Marcela Vignoli

Instituto Superior de Estudios Sociales, Consejo Nacional de Investigaciones Científicas y Técnicas. Facultad de Ciencias Naturales e Instituto Miguel Lillo, Universidad Nacional de Tucumán, Argentina.

Correo electrónico: vigmarce@gmail.com

Artículo recibido: 05 de junio de 2020 Aprobación final: 23 de octubre de 2020

\section{Resumen}

Luego de participar en la segunda reunión del Consejo Internacional de Mujeres (Londres, 1899) la médica Cecilia Grierson junto con mujeres de trayectoria pública vinculada a la Sociedad de Beneficencia de la Capital Federal, crearon el Consejo Argentino en el que durante la primera década del siglo XX ingresaría un centenar de asociaciones femeninas, con una marcada preponderancia de las filantrópicas, de caridad y religiosas. Es muy conocida la ruptura del Consejo de 1910, que precipita la salida de las universitarias. Sin embargo, es menos conocido el consenso al que llegaron grupos tan diversos en sus orígenes.

A partir de considerar los intereses de clase y profesionales que se pusieron en juego, esta investigación se interroga especialmente por el rol que tuvo Grierson en los orígenes de esa creación, los contactos previos con diferentes grupos de mujeres y los vínculos internacionales que le permitieron concretar esta formación. Una vez explorada la creación del Consejo, analizaremos también las primeras inquietudes socio-económicas que las llevaron a ensayar proyectos en materia legislativa, como el de protección a la maternidad y el de incorporación de la economía doméstica en la agenda de la asociación y del Estado argentino. 


\title{
Cecilia Grierson and the Ladies of the Official Beneficence at the Origins of the National Women's Council of Argentina (1887-1906)
}

\begin{abstract}
After participating in the II meeting of the International Council of Women, celebrated in London in 1899, doctor Cecilia Grierson completed the creation of the Argentine Council, in alliance with women of public trajectory linked to the Buenos Aires's Benefit Society, During the first decade of the twentieth century, a hundred of women's associations of various kinds - with a strong preponderance of philanthropic, charitable and religious- entered to this council. Extant literature has shown that this alliance was broken in 1910, precipitating the leave of graduated women. However, the consensus reached by such diverse groups in their origins is less known. Considering both class and professionals interests at stake, this research asks about the role played by Cecilia Grierson in the origins of that Council. It also investigates the previous contacts with different groups of women and the international links that allowed her to establish this organization. Then, we will explore the first socio-economic concerns in legislative matters that they developed, such as the maternity protection project and the attempt to incorporate the domestic economy into the Association's and the Argentine State's agendas.
\end{abstract}

Keywords: Cecilia Grierson, Graduated Women, Beneficence, Feminism, Domestic Economics.

\section{Introducción}

Cuando Cecilia Grierson ${ }^{1}$ (Buenos Aires, 1859 - Buenos Aires, 1934) regresó a la Argentina luego de participar en la segunda reunión del Consejo Internacional de Mujeres llevada a cabo en Londres en julio de 1899, ya no tenía dudas respecto de los beneficios que aportaría la creación de una asociación en el país que estuviera vinculada al ambiente internacional. Durante más de treinta años atesoraría documentos que le recordaban el congreso, ${ }^{2}$ y que atestiguan de qué modo impactó en ella esa reunión de "[...] mujeres inteligentes que sabían

1 Cecilia Grierson fue la primera médica argentina, recibida en la Universidad de Buenos Aires en 1889. Se dedicó a la ginecología y a la obstetricia. En 1891 fue uno de los miembros fundadores de la Asociación Médica Argentina y un año después fundó la Sociedad Argentina de Primeros Auxilios y pasó a formar parte de la Cruz Roja Argentina. Fue integrante del Consejo Nacional de Educación entre 1892 y 1899. Enviada por el Gobierno nacional, viajó este último año a Europa. La experiencia le permitió traer al país un nuevo plan de estudios profesionales centrado en la educación técnica de la mujer. Durante el viaje, asimismo, participó en Londres en el II Congreso del Consejo Internacional de Mujeres y luego realizó cursos de perfeccionamiento en ginecología y obstetricia en París. Además, visitó clínicas y hospitales en Viena, Berlín y Leipzig. Al llegar a la Argentina comenzó las gestiones para fundar el Consejo Nacional de la Mujer, concretado al año siguiente.

2 Una fotografía de la presidenta del International Council of Women, un programa del evento, la disertación que expuso ante tres mil personas en Londres, cartas manuscritas, recortes periodísticos, libros de su autoría, otras fotografías así como objetos y una serie de biografías componen el archivo personal de Grierson existente en el Departamento de Colecciones Especiales y archivo de la Biblioteca Max Von Buch de la Universidad de San Andrés. Agradezco especialmente a Natalia Westberg y a Silvana Piga, quienes me facilitaron la consulta de este material. 
expresarse, raciocinar y discutir con tanta calma como un hombre [...] tuve ocasión de admirar la serena elocuencia de las norteamericanas, su acostumbrado hábito de discutir ordenadamente y manejar asambleas de forma parlamentaria, su espíritu independiente y emprendedor". ${ }^{3}$ En el marco del encuentro, había percibido por otra parte el profundo desconocimiento que sobre la Argentina tenía esa comunidad internacional. ${ }^{4}$ De modo que la creación de una asociación local tenía para Grierson un doble propósito: acercar esos "mundos de mujeres"” al país y dar cuenta de la realidad femenina de una región todavía exótica para gran parte de la comunidad mencionada.

En función de esta idea comenzó a reunirse con mujeres de sectores medios y altos para proyectar la creación de lo que en un principio se llamaría Consejo Nacional de Señoras, concretado el 25 de septiembre de 1900 en la casa particular de Albina Van Praet de Sala, quien se había desempeñado como presidenta de la Sociedad de Beneficencia de la Capital Federal entre 1898 y 1899. ${ }^{6}$ Albina de Sala sería la primera presidenta del Consejo Nacional de la Mujer en la República Argentina (en adelante CNMAR), cargo que ejercería hasta su muerte en 1918.

La historiografía interesada en los orígenes del movimiento de mujeres de Argentina ha vuelto la mirada al Consejo, principalmente para centrar la atención en un episodio que ocurrió diez años después de fundado y que oficia como parteaguas en la historia del feminismo en el país. Efectivamente, en 1910 el CNMAR no resistió las diferencias que habían comenzado a plantearse dos años antes entre la asociación de universitarias y su cúpula. Es muy conocido el resultado de este conflicto que precipitó la salida de las universitarias, escisión materializada durante la organización de dos congresos con motivo de la conmemoración del Centenario de la "Nación argentina".

También es muy conocido el texto escrito por Grierson una vez fuera del Consejo, en el que señala diferencias entre el grupo de universitarias y las mujeres interesadas en la beneficencia y la caridad, que habrían llevado a la ruptura y a lo que consideró "la decadencia del Consejo Nacional de Mujeres" (Grierson, 1910). Este episodio de 1910 también sirvió de lección para que el flamante Consejo uruguayo no repitiera esos errores al fundarse en 1916. Por esos años, Petrona Eyle escribía

3 (Diciembre de 1902), Revista del Consejo Nacional de la Mujer en la República Argentina, núm. 8, pp. 28- 29.

4 "En ese memorable congreso -escribía Cecilia- la América del Sud no estaba representada sino por Argentina, y de ahí los momentos amargos que pasé, me encontraba con señoras muy instruidas, pero que ignoraban por completo el punto del globo en que quedaba la Argentina. Aún más, en la lista del congreso fue colocada al principio entre la China y Persia! (diciembre de 1902), Revista del Consejo Nacional de la Mujer en la República Argentina, núm. 8, p. 28.

5 La expresión fue acuñada por Leila Rupp. La autora plantea que desde fines del siglo XIX las mujeres construyeron una especie de identidad internacional colectiva cuyas raíces pueden rastrearse en redes de comunicación preexistentes entre mujeres viajeras, escritoras, migrantes, misioneras, editoras de periódicos y autoras de libros y cartas, quienes establecieron contactos para mantener interacciones más formalizadas. Asimismo, una variedad de movimientos sobre abolicionismo, temperancia, socialismo, paz y reformismo moral Ilamaron la atención de mujeres de otras naciones. Esos "mundos de mujeres" se articularon en torno de tres asociaciones internacionales, International Council of Women (1888), International Women Suffrage Alliance (1904), Women's International League for Peace and Freedom (1915). Ver Rupp (1997: 14-15). Las cursivas nos pertenecen.

6 Durante los años 1909-1910 volvería a ocupar el mismo cargo. Cfr. Correa Luna (1925). 
a la médica uruguaya Paulina Luisi haciendo notar que si bien se podía constatar que el feminismo había progresado en el mundo desde 1900 “[... ] nuestro consejo ha retrocedido más bien. La clásica frase de la señora de Sala 'no estamos aún preparadas' sigue siendo de actualidad en la fecha de hoy" (Cuadro Cawen, 2018: 185). Según esta interpretación, la cúpula del CNMAR habría sido responsable de una oportunidad desperdiciada para la circulación del feminismo en Argentina. Luisi habría tomado la posta del feminismo en la región y logrado que el caso de Uruguay sí fuera exitoso, a juzgar por la inserción internacional conseguida, pero sobre todo por la conquista del voto femenino en la década de $1930 .^{7}$

Algunos autores/as se centraron únicamente en el episodio de 1910 y consideraron que las diferencias entre las universitarias y las damas de la beneficencia estuvieron presentes desde los orígenes del Consejo argentino (Fletcher, 2004; GirbalBlacha, 2006; Lobato, 2010; Recalde, 2010). Incluso, y a pesar de haber perdurado durante ocho años, se llegó a afirmar que esta era "[...] una alianza de intereses inviable" (Morrone, 2016: 134). Otras autoras matizaron esta idea mostrando los vasos comunicantes entre ambos espacios, que se expresaban en coincidencias respecto de la educación de las mujeres y en el común interés por la cuestión social y la niñez (Barrancos, 2002; Guy, 2011; Gluzman, 2013, Cuadro Cawen, 2018).

Por su lado, otras investigaciones que analizaron la dinámica del CNMAR desde sus orígenes y no sólo la ruptura del Centenario, aportaron una proyección de más largo plazo a través de la cual fue posible trazar algunas trayectorias o conocer alianzas con otros grupos situados fuera del Consejo (Carlson, 1988; Lavrin, 1997; Nari, 2000; Vasallo, 2000; Sowles Hammon, 2004; Martínez Prado, 2015 y Vignoli, 2018).

En cuanto a las investigaciones centradas en la vida de Grierson, consideramos por nuestra parte que sus logros académicos en los campos de la medicina y la educación femenina en un contexto signado por la inferioridad jurídica de las mujeres contribuyeron a forjar una imagen idealizada de su rol en los orígenes del feminismo argentino, asumiendo que ella abrazaba esta causa incluso antes de crear el Consejo. Partiendo de esta última perspectiva, no resultó fácil explicar, y ni siquiera constituyó una pregunta dentro de la historiografía argentina, cómo fue que una feminista logró en 1900 construir un proyecto asociativo con mujeres para las cuales el movimiento era demasiado exótico para implementarse en la Argentina. Y cómo fue que esa vinculación se mantuvo al menos durante ocho años en momentos en los que había ya mujeres en otros grupos y asociaciones que explícitamente y sin eufemismos se autodefinían feministas. ${ }^{8}$

7 La investigadora norteamericana Katherine M. Marino (2019) refuerza esta idea cuando comienza su estudio sobre las experiencias feministas del Cono Sur, focalizando en Paulina Luisi y el caso uruguayo. Sin embargo, consideramos que debido a la influencia de feministas porteñas en la formación de Luisi con anterioridad a 1910, y al vínculo que continuaron sosteniendo con ella (que las llevó a confluir y coorganizar encuentros internacionales, como muestra la profusa relación epistolar entre unas y otra), muy difícilmente los orígenes del feminismo uruguayo puedan explicarse sin mencionar las ideas feministas circulantes desde los últimos años del siglo XIX en Buenos Aires. En efecto, la circulación de ideas y personas entre Montevideo y Buenos Aires era tan intensa que podría incluso postularse la existencia de un feminismo rioplatense durante esta etapa.

8 En 1902 María Abella Ramírez creaba en la ciudad de La Plata la revista Nosotras, autodenominada 
Es decir, la alianza de Grierson con las mujeres dedicadas a la filantropía no fue abordada en profundidad o de modo plenamente satisfactorio por la bibliografía precedente. En efecto, ella fue examinada sin demasiadas precisiones (Lonarica, 1976) o se vio en términos de una más entre las muchas que tuvo (Binda et al., 2012; Pérgola, 2015); o fue pensada como una alianza destinada a romperse (Morricone, 2016); o bien la participación de Grierson dentro del Consejo fue idealizada al considerársela como parte de su militancia feminista (Martin, 2020: 77).

Lo cierto es que los estudios consultados arrojan muy poca información sobre las instancias previas a la creación del CNMAR y el papel que jugaron Grierson y las damas de la beneficencia oficial ${ }^{9}$ hasta lograr establecer la Asociación. ¿Cómo llegaron a configurarse los lazos entre ellas? ¿Cuáles fueron los intereses en común? ¿Qué lugar tuvo la discusión sobre el feminismo en su interior? ¿En qué proyectos se apoyaron mutuamente? La hipótesis que orienta esta investigación está articulada en torno a estos interrogantes; consideramos que responder a ellos puede contribuir a iluminar los inicios de una asociación clave en el movimiento de mujeres de principios de siglo. Así, sostenemos que en los orígenes del Consejo el feminismo abrazado por Grierson y las universitarias hacia 1910 era más bien difuso e impreciso, objeto de lecturas e interés pero considerado aún extravagante para implementarse en el país, algo que ni siquiera llegó a discutirse. Durante cierto tiempo esta posición se mantuvo en casi todos los grupos que integraban el CNMAR y no sólo entre las mujeres de la beneficencia.

En este sentido, volvemos la mirada sobre esos momentos iniciales para entender el juego de acuerdos, alianzas e intereses personales que permitieron a grupos aparentemente tan diversos converger en torno de la idea de fundar la asociación y convivir en armonía durante al menos ocho años, lo cual, en términos asociativos y para una época en la que predominaba un asociacionismo de tipo efímero y disperso, no es poco tiempo.

Para realizar esta investigación fue fundamental contar con fuentes que permitieron acercamientos en diferentes escalas a la etapa formativa del Consejo. Tuvimos acceso por una parte a los documentos del Consejo Internacional de la Mujer (específicamente los relativos a los años que fue presidido por May Wright Sewall entre 1899 y 1904) conservados en la Biblioteca William Oxley Thompson de la Universidad Estatal de Ohio y en repositorios digitales a los que dicha biblioteca se encuentra suscripta, como Sophía Smith Collection. La revisión de este material hizo posible, por una parte, delimitar las características asumidas por la integración argentina en la comunidad femenina internacional que tuvo lugar a través del Consejo, y, por otra, constatar las expectativas de la propia

primera revista feminista de la Argentina. En 1906, el Congreso de Librepensamiento organizado por la masonería planteaba un programa feminista, que se reforzaría a través de la gira que la española Belén de Sárraga emprendió por el país. El mismo año, Elvira Rawson de Dellepiane -a la sazón, la segunda médica del país- creaba el Centro Feminista Argentino, del que formarían parte Julieta Lanteri, Alicia Moreau de Justo y otras de las primeras universitarias (Bianchi 1986; Valobra 2008; Mollés 2013; Barrancos 2014a; Cuadro Cawen 2018; Vignoli 2019a).

9 Seguimos a Valeria Pita al utilizar la expresión "beneficencia oficial" (y no filantropía o caridad) para hacer referencia a la Sociedad de Beneficencia, que luego de la federalización de Buenos Aires pasaría a llamarse Sociedad de Beneficencia de la Capital Federal. Pita (2012: 18). 
Sewall en este primer consejo que se fundaba en el Cono Sur. La consulta de la colección de la Revista del Consejo Nacional de la Mujer de la República Argentina, disponible en la Biblioteca Nacional Mariano Moreno, posibilitó asimismo percibir la importancia adquirida por la dimensión internacional en la etapa estudiada; las minuciosas transcripciones de la correspondencia mantenida con otros Consejos del mundo allí publicadas fueron en este sentido de gran valor. Sin embargo, los detalles del día a día de la institución expuestos en esta publicación no fueron suficientes para conocer en profundidad el ambiente que en el plano local permitió la gestación del Consejo. Fue el cruce de la información ofrecida por esa revista con escritos incluidos en el Fondo documental Cecilia Grierson disponible en la Biblioteca Max Von Buch, el que nos permitió percibir las redes personales e institucionales que propiciaron su creación. Tal operación hizo visible que los aceitados vínculos entre Grierson y las damas de la beneficencia oficial se habían forjado varios años antes.

Vale la pena mencionar la importancia de este archivo personal para el logro del objetivo específico de la investigación. El análisis de estos papeles permitió apreciar la dosis de incertidumbre y expectativa de quienes estuvieron involucradas en la creación del Consejo. Mostró que estas mujeres estaban muy lejos de pensarla como una empresa destinada al fracaso, como señaló parte de la historiografía; expuso, que, por el contrario, confluyeron en su surgimiento firmes motivaciones y convicciones personales, febriles negociaciones de último momento y ostentación de capital económico, político e intelectual, no siempre visibles en el órgano de difusión de la asociación, que procuraba mostrar un relato de intereses colectivos homogéneos.

\section{Las relaciones entre la Sociedad de Beneficencia oficial y Cecilia Grierson}

Sin duda, un contexto opresivo para la vida pública y privada de las mujeres -producto de la normativa vigente en el Código Civil, elaborado por Vélez Sarsfield- es un factor que permite explicar una alianza en la que mujeres de distintos sectores se sintieron interpeladas para la creación de un espacio que les permitiera revertir su desventajosa situación a través, por ejemplo, de iniciativas legislativas. Como indica Dora Barrancos, "Al finalizar el siglo XIX ya estaba en plena vigencia el Código Civil que sancionaba la inferioridad jurídica de las mujeres [...] No puede sorprender que desde mediados de aquel siglo se extendieran las acciones femeninas para revocar esa insidiosa circunstancia” (Barrancos 2014b: 8). Aunque en el Consejo hubo opiniones distintas respecto del alcance que debía tener la capacidad jurídica, es evidente que su creación obedeció a un deseo de conquistar derechos en el entendimiento de que ello no sería producto de iniciativas individuales. ${ }^{10}$

10 De hecho, a poco de creado el CNMAR, uno de los objetivos de sus integrantes fue lograr la personería jurídica (obtenida en agosto de 1902), que las habilitaría a presentar proyectos legislativos. El primero fue el relativo a la protección a la maternidad. Volveremos más adelante sobre esta cuestión. 
Además, en la alianza para crear el Consejo argentino es posible que también hayan intervenido intereses personales, de clase y profesionales que venían pautando las relaciones previas de Grierson y otras universitarias con las mujeres interesadas en la filantropía. Por ejemplo, las estudiantes y primeras médicas argentinas podrían haber necesitado contactos con las poderosas asociaciones de beneficencia si pretendían ocupar cargos en instituciones vinculadas a la salud, como hospitales o asistencias sanitarias. Por su parte, si consideramos las motivaciones de las damas de la beneficencia oficial para integrar la Asociación, cabe preguntarse si, pensando que una eventual conducción del Consejo otorgaría poder e información sobre todo el arco asociativo presente en el país, estas mujeres consideraron que resultaba una buena idea refugiarse en una asociación descle la cual podrían proyectar una imagen nacional pero sobre todo internacional de mucha fortaleza.

Es que a pesar de que la creación del Consejo tuvo lugar en un momento en el que la beneficencia, la filantropía y la caridad todavía ostentaban un gran prestigio entre las tareas femeninas públicas, ${ }^{11}$ la beneficencia oficial venía sufriendo embates por parte del Estado. Al respecto, conviene detenernos en la gran pérdida que significó para la Sociedad de Beneficencia de Buenos Aires -con motivo de la sanción de la Ley de Educación Común- entregar el control de las escuelas para niñas en enero de 1876 al Consejo General de Escuelas de la Provincia, cuyo director no era otro que el mismo Domingo F. Sarmiento. Esta quita formó parte del proceso de construcción del Estado que se dio en las últimas décadas del siglo XIX y que llevaría a esta asociación, pero también a la Iglesia (el matrimonio civil fue sancionado unos años después), a ceder gran parte de las prerrogativas acumuladas a lo largo del siglo, producto de la delegación de funciones que el Estado había realizado en áreas tan importantes como la de la educación, por ejemplo. ${ }^{12}$ Aunque recientemente Laura Ramos (2021: 95) ha postulado que luego del desconcierto inicial, las damas de la Sociedad de Beneficencia pusieron todas sus energías en la creación de una escuela para niñas de la alta sociedad porteña, lo cierto es que esta transferencia hacia el Ejecutivo nacional, que fue caracterizada como "crucial para la consolidación de un orden político de fuerte tono centralista” (Botana y Gallo, 1997: 35), despojaba a la asociación de la injerencia que en materia educativa tenía desde hacía medio siglo.

En efecto, la primera de las atribuciones que había encomendado Bernardino Rivadavia a la Sociedad de Beneficencia al crearla en 1823 era la dirección e

11 Hay consenso en torno de la idea de que la Sociedad de Beneficencia creció luego de la federalización de Buenos Aires (Moreno 2009; De Paz Trueba 2010 y Pita 2012). En efecto, hacia 1880 tenía a su cargo tres hospitales, la Casa de expósitos, un consultorio oftalmológico, un correccional de mujeres y dos establecimientos para huérfanas; contaba por otro lado con cincuenta y siete años de ejercicio en la vida pública porteña. "[...] los años 1880 se iniciaron con un renovado aval político para el ejercicio de la beneficencia pública que se fue consolidando en una estrecha alianza con el poder nacional. A partir de entonces, inserta en el organigrama nacional [...] se transformó en la dependencia asistencial más poderosa en finanzas, empleados e instituciones del territorio argentino siendo a su vez la principal responsable de dar forma a las respuestas oficiales respecto al abandono de niños y niñas y a la enfermedad y a la pobreza en clave femenina" (Pita 2012: 166-167).

12 Los datos del control sobre la educación que tenía la Sociedad de Beneficencia son elocuentes. De acuerdo con la memoria de 1874, contaba con 37 establecimientos con 3.356 alumnas en la ciudad, y 61 establecimientos con 4.388 alumnas en la campaña. Es decir que, a lo largo del territorio de la provincia de Buenos Aires, manejaban 7.744 escolares distribuidas en 98 casas de educación. Información obtenida de Carlos Correa Luna (1925: 209-210). 
inspección de las escuelas de niñas. Al hacer entrega de las escuelas al ex presidente Sarmiento, a mediados de la década de 1870, su presidenta, Dolores Lavalle de Lavalle, manifestaba desafiante, pero con indisimulado dolor, la pérdida que significaba para la Sociedad de Beneficencia ser privadas del papel tan trascendente que habían desarrollado por décadas al frente de la educación femenina:

La Sociedad no puede ocultar a VS el sentimiento desinteresado con que se ha desprendido de numerosas maestras, de las infinitas alumnas que pueblan las escuelas en la ciudad y campaña, fundadas por ella, y por ella administradas. Muchas de estas maestras han sido formadas en la escuela normal creada por la Sociedad con este objeto, en la cual han adquirido una educación tan general y científica como puede desearse en los países más adelantados.

Esto nos lleva a interrogarnos por las motivaciones que incidieron en las integrantes de la Sociedad de Beneficencia de la Capital Federal para involucrarse en la creación y dirección del Consejo, ${ }^{14}$ ya que fueron ellas, en el marco de ese período "de suma debilidad política" de la institución (Pita, 2012: 22), las que se interesaron en el proyecto del CNMAR. ${ }^{15}$ Además, no debemos dejar de mencionar el interés que suscitó en alguna de estas mujeres entrar en contacto con novedades femeninas y feministas. Es probable que la circulación de estas ideas y el acercamiento a un mundo en el que mujeres de otras extracciones sociales compartían con ellas algunas inquietudes, así como la posibilidad de constituirse en intermediarias entre una comunidad internacional y una población femenina local en clara desventaja respecto de los varones en cuestiones de derechos, fueran percibidas como un modo de compensar el terreno perdido en materia de instrucción de mujeres.

Por último, como dijimos, en la alianza para crear el Consejo argentino también podrían haber jugado intereses profesionales que venían pautando las relaciones entre Grierson y algunas de las mujeres pertenecientes a la Sociedad de Beneficencia que se interesaron por el proyecto. Esto se explica, sobre todo, por la injerencia que comienza a tener la Sociedad de Beneficencia a partir de 1870 en el Hospital de Mujeres. Como indica José Luis Moreno, a la relación que las damas tenían con las elites políticas "que pugnaban por un país moderno y por una república con ciudadanos consustanciados con el progreso y la civilidad” se sumó una "apertura de carácter científico", al ceder a la Facultad de Medicina una sala del mencionado hospital a los efectos de dictar cursos y llevar a cabo prácticas médicas (Moreno, 2009:40-41). A pesar de que la modalidad de esos años -en la que la Sociedad proponía sus médicos para el Hospital de Mujeres- fue modificándose hasta que en la década de 1880 estos cargos se cubrían mediante concursos, la Asociación continuó incidiendo en esta institución, lo que estaba claro también

13 Manifiesto dirigido al Gobierno al hacer entrega de las Escuelas, 1876. Ver Correa Luna (1925: 210).

14 En efecto, Albina Van Praet de Sala, Dolores Lavalle de Lavalle, Carolina García Lagos, Jean Thomson Raynes y Julia Moreno de Moreno formaron parte, junto a Grierson y otras mujeres, de la primera comisión directiva del Consejo.

15 Para un análisis del sesgo ideológico impreso por Rivadavia a la Sociedad de Beneficencia puede verse Parra (2001: 100-108). 
para la corporación de médicos. Siendo todavía estudiante de medicina, Grierson tomó contacto con Luisa Muñoz de Cantilo, que en 1887 presidía la Sociedad de Beneficencia de la Capital Federal, para solicitar su ingreso como "practicante honoraria interna" en el Hospital de Mujeres. Fundaba su pedido en que ya había sido "practicante externa" desde su ingreso en la Facultad de Medicina, puntualizando que " [...] las Señoras de la Sociedad de Beneficencia serán las primeras en facilitar los medios de estudio a las que como yo quieren dedicarse con especialidad a las enfermedades que a las de su sexo concierne [...]" ${ }^{16}$ La respuesta de Cantilo, cuatro meses después, no sólo concedía el pedido, sino que le informaba que recibiría un sueldo mensual de 60 pesos m/n. En 1888, Dolores Lavalle de Lavalle, presidenta de la misma asociación, le informaba que el gobierno había aprobado su designación como "practicante menor" en el Hospital Rivadavia (de Mujeres) ${ }^{17}$ Unos meses después se le otorgaba el cargo de "practicante mayor", que Grierson había obtenido mediante concurso en la Facultad.

A esta actividad se sumaba su nombramiento como miembro de la Tercera Sección de Salas Cunas y Asilos maternales a cargo del "Patronato de la Infancia". ${ }^{18} \mathrm{El}$ ingreso al Patronato significaría para Grierson mucho más que una oportunidad laboral o la integración a un ambiente de sociabilidad de índole benéfico. Implicaría también entrar en contacto con la circulación de ideas en el plano internacional. Como consignó Dora Barrancos, todo indica que el primer empleo público de la voz "feminismo" en Argentina se habría dado en 1898, a raíz de la propuesta de una sección especializada "en las contribuciones femeninas", realizada por las mujeres del Patronato de la Infancia en el marco del compromiso de efectuar una exposición preparatoria de la que tendría lugar en París en 1900. Desde los primeros meses de 1898, los medios periodísticos de Buenos Aires informaron sobre la nueva actividad que desarrollaban las damas del Patronato, todas integrantes de la élite económica porteña, que preparaban la sección "femenil” de la exposición. Rápidamente, los grandes diarios comenzaron a designar a esta iniciativa como la "Sección Feminista" de la exposición nacional (Barrancos, 2005). ${ }^{19}$

Como veremos más adelante, esta trama de relaciones entre Grierson y las damas de la beneficencia oficial, la filantropía y la caridad, que empieza a tejerse a mediados de la década de 1880, fue fundamental cuando quince años después comenzó a tomar forma la idea de crear una asociación de mujeres con proyección nacional que estuviera vinculada a la comunidad femenina internacional.

16 Biblioteca Max Von Buch, Buenos Aires (en adelante, BMVB), Fondo documental Cecilia Grierson. CG1 14, 2. En efecto, la tesis de Grierson, Histero-ovariotomias efectuadas en el Hospital de Mujeres desde 1883 a 1886 fue presentada en 1889 en la Facultad de Ciencias Médicas de la Universidad de Buenos Aires para optar al grado de Doctor en Medicina y Cirugía. Recuperado de: http://repositoriouba. sisbi.uba.ar/gsdl/cgi-bin/library.cgi?a=d\&c=amdtesis\&d=Tesis_00890_Histero_ovariotomias_en_hospital_de_mujeres_de_1883_a_1889_Grierson_Cecilia_1889_oai (10 de noviembre de 2019).

17 BMVB, Fondo documental Cecilia Grierson, CG1, 16.

18 BMVB, Fondo documental Cecilia Grierson, CG1 23. Unos meses después, era elegida Secretaria de la Sub comisión de salas cunas, de la que el Dr. Leopoldo Montes de Oca era el presidente.

19 A fines del siglo XIX, en el proceso de internacionalización de las asociaciones de mujeres, las exposiciones universales fueron utilizadas por las feministas, que advirtieron el potencial que las ferias ofrecían para tejer conexiones transnacionales y crear un apoyo internacional para sus reclamos sobre igualdad. Los congresos de mujeres sobre derechos se realizaban a la par de las exposiciones universales y otras exhibiciones que permitían a las mujeres organizarse. Este tema está abordado en Boussahba-Bavard y Rogers (2017). 


\section{Cecilia Grierson en el Congreso de 1899 de Londres}

El International Council of Women había sido creado en 1888 en Washington, y en 1893 organizó su primer encuentro en Chicago. Isabel King, una de las sesenta y cinco maestras norteamericanas que habían llegado a la Argentina en el marco del proyecto de Sarmiento, ${ }^{20}$ fue invitada por May W. Sewall -a quien conocía del ambiente de sociabilidad de índole educativo-cultural de Indianápolis- a representar a las mujeres de Sudamérica. Para recopilar datos, Isabel se puso en contacto con Grierson, quien la vinculó con las mujeres de la beneficencia oficial. Le presentó así a Carolina García Lagos, que aportó información sobre Uruguay, y a Dolores Lavalle de Lavalle, "[...] de histórico abolengo y de notoria actividad de beneficencia en nuestro país. Ambas le dieron datos, estadísticas y folletos para su informe". ${ }^{21}$ Al regresar de la reunión en Chicago, Miss King -como se la conocía en el ambiente educativo- pensó que la persona más apropiada para representar a la Argentina sería la esposa del presidente, “[...] fundándose en el papel tan activo que toman en Europa y EEUU las esposas de los gobernantes y diplomáticos. Pero desgraciadamente creo que ni se contestó a ese acto de cortesía”. ${ }^{22}$

Para el siguiente congreso, que se realizaría en Inglaterra en 1899, la presidenta del ICW contactó a Jean Thompson de Raynes como presidenta de la asociación "The International Home" ${ }^{23}$ una de las primeras que se incorporaron al CNMAR en 1900, a fin de que sugiriera quién podría viajar a Europa y representar a la Argentina en el encuentro. Fue así que se estableció contacto con Grierson, que se disponía precisamente a emprender un viaje a Europa y se consiguió "Con la premura del tiempo [...] que nueve sociedades de señoras firmaran la

20 Isabel King había llegado a la Argentina en 1883 junto con su hermana Rachel, procedentes de Indianápolis. Enseñaron en la Escuela Normal de Catamarca y en la de Concepción del Uruguay. Luego, en 1887, pasaron a la recientemente creada Escuela Normal de Goya, en Corrientes. En 1893 ambas volvieron a Estados Unidos. Rachel lo hizo definitivamente, para continuar en Boston especializándose en jardines de infantes, mientras que Isabel retornó dos años después a la Argentina, primero a la Escuela Normal de Goya y luego a la de Concepción del Uruguay, donde se estableció definitivamente. De hecho, una asociación surgida de esta escuela, la "Sociedad Escuela Normal de Mujeres de Concepción del Uruguay" integró el Consejo Nacional de la Mujer en Argentina desde sus orígenes. Para un análisis de las maestras norteamericanas, cfr. Crespo (2006).

21 (diciembre de 1902) Revista del Consejo nacional de la mujer en Argentina, núm. 9, , p. 27. Este perfil de Dolores Lavalle de Lavalle coincide con el trazado por Valeria Pita. Según Pita fue "una de las líderes más pujantes y clave de la Sociedad en los años 1870". En ese contexto no sólo fue la encargada de transferir las escuelas al Estado en 1876, sino que también debió resolver situaciones de arbitrariedad en el ingreso de mujeres al hospicio, desafiando el Código Civil vigente desde 1869 (Pita 2012: 148).

22 (diciembre de 1902) Revista del Consejo nacional de la mujer en Argentina, núm. 8, p. 29. La referencia corresponde a Cipriana Lahitte, esposa de Luis Sáenz Peña, presidente de la Argentina entre 1892 y 1895. Sabemos que Cipriana había sido presidenta de la Sociedad de Beneficencia en momentos en los que se avizoraba la quita de la injerencia en el área educativa femenina, motivo por el que terminó renunciando. Información obtenida de Pita (2012: 134). Probablemente este sinsabor haya incidido a la hora de rechazar su participación en el Consejo Nacional de Mujeres.

23 Esta asociación, fundada a principios de 1899, perseguía el objetivo de "amparar a toda mujer y proteger a las jóvenes que se encuentran sin recursos, cualquiera sea su nacionalidad o religión, enseñándoles cuando sea necesario el mejor camino para ser independientes por medio del trabajo honrado". Con ese propósito se había diseñado un registro de colocaciones publicitado a través de carteles pegados en barcos que se dirigían de Europa a Buenos Aires, en estaciones de ferrocarriles y en distintos establecimientos públicos. Sus miembros se ufanaban de que en el curso de un año habían tenido 149 pensionistas de diferentes nacionalidades y logrado dar empleo a 287 personas. La asociación contaba con 117 socias, las que colaboraban con cuotas. Además de este ingreso, se sostenía con reuniones anuales como "venta del delantal" $y$ "pound party". En particular, Raynes se destacaría dentro del Consejo por su lucha contra la llamada trata de blancas. (julio de 1901) Revista del Consejo nacional de la Mujer en Argentina, núm. 2, p. 7. 
autorización para representarlas ante el consejo”. ${ }^{24}$ Próxima a partir, en abril de 1899, el Ministerio de Relaciones Exteriores de la Argentina recomendaba a los agentes diplomáticos (consulares y autoridades de tránsito) que le prestaran auxilio en todo lo que necesitara durante su viaje.

Una vez en el Congreso, Grierson nombrada vicepresidenta honoraria y la presidenta del ICW, May Wright Sewall, la invitó a hablar en la inauguración ante un auditorio de tres mil personas. En su disertación, dedicada al tema "Educación y trabajos de la mujer en la Argentina"25, y después de pedir disculpas por no exponer en inglés, presentó a la Argentina como un país "[...] de libertad [...] un pueblo nuevo, cosmopolita [...] nuestras tierras, instituciones y riquezas están abiertas al mundo entero". Graficaba esta referencia a la inmigración, asegurando que "la mayoría habla dos o tres lenguas, tienen amplitud de miras y son de sentimientos generosos". Repasaba también las obras de arquitectura y embellecimiento de las ciudades del país y aludía en especial en este marco a los edificios de ciencia y filantropía. Destacaba el crecimiento de Buenos Aires por sobre las demás provincias, aportando datos respecto de la cantidad de habitantes y las inversiones que algunas empresas extranjeras (principalmente inglesas y norteamericanas) habían realizado.

Luego se concentraba en la situación laboral de las mujeres. Focalizaba en primer lugar en las de la campaña, describía sus trabajos y el cuidado que ponían en la crianza de sus hijos en cuanto a aseo, alimentación, vestimenta. Distinguía a las extranjeras, que "hacían trabajos de fuerza", de las restantes, que se concentraban en sus quehaceres domésticos y a lo sumo ayudaban a sus familias en tareas de lavado, planchado o cocina. Cuando explicaba por qué las mujeres no trabajaban fuera de su casa, enfatizaba la vergüenza que muchas todavía sentían al demostrar que necesitaban trabajar para sobrevivir. Aseguraba que era esta la razón por la que "[...] muchas soportan la pobreza o viven de la caridad antes que dejar ver que necesitan trabajar [...]”. De ese modo, tareas más calificadas como la "[...] confección artística fabricando corsés, guantes y como modistas de sombreros para lo cual hay gran consumo porque se paga muy bien todo lo que sea elegante y de moda [...] han pasado a manos extranjeras, especialmente francesas [...] las extranjeras hoy en día prefieren el trabajo en nuestras nuevas fábricas que les da más independencia y mayor libertad, en vez de dedicarse al trabajo doméstico”. A continuación enumeraba diferentes ocupaciones femeninas: trabajos comerciales en tiendas por mayor, empleo como escribientes o copistas, labores de ebanistería, trabajo en oficinas telegráficas y de telefonía.

Teniendo en cuenta estos señalamientos, conviene destacar que si bien es cierto que, al contrario de lo que ocurría con los varones, el trabajo femenino debía ser "socialmente aceptable", no lo es menos que, como demostró Graciela Queirolo, “[...] muchas trabajadoras permanecieron en el mercado a lo largo de sus vidas o bien realizaron más de un ingreso según sus circunstancias biográficas 
entre las que deben contemplarse los anhelos de bienestar material cuando no los de autonomía social [...]". Siguiendo a la autora, muchas mujeres que trabajaban en sus hogares lo hacían para resolver el cuidado de sus hijos, o "con la vana ilusión de compatibilizar la tarea de cuidado con las de asalariadas" (Queirolo, 2018: 42-43).

Volviendo a la conferencia de Grierson, ella se detenía también en las mujeres dedicadas a la beneficencia; distinguía la obra realizada por éstas "[...] para aliviar la miseria y el sufrimiento [...] la filantropía y caridad está completamente en sus manos, y nuestras más ilustres, hermosas y ricas damas administran generosamente para nuestro gobierno una de las secciones más bastas [sic.] de trabajos de hospitales y otras caridades". Su mirada focalizaba en particular la Sociedad de Beneficencia de la Capital, señalándola como la primera de esas asociaciones y enfatizando que si bien había perdido el control de escuelas comunes, continuaba manejando hospitales y orfanatos. Informaba, por otra parte, sobre la existencia de asociaciones similares en todo el país, y reparaba en una sociabilidad que comenzaba a asomar y que era de otra índole al mencionar la existencia de "[...] algunas bastantes adelantadas para proteger las trabajadoras intelectuales que en las provincias son las estudiantes de las escuelas normales". ${ }^{26}$

Vale la pena detenernos en este punto para aclarar que la participación femenina en asociaciones de índole cultural creadas por varones (bibliotecas populares, centros literarios o asociaciones patrióticas), fue muy esporádica y ceñida a determinados roles. Por lo general, aquellas que ingresaban lo hacían mediante una invitación especial para ocupar membresías honorarias luego de comprobarse que se habían destacado dentro de la literatura o el periodismo, o bien eran invitadas a disertar en alguna ocasión, pero muy raramente integraban comisiones directivas o tenían la posibilidad de votar. ${ }^{27}$ Por supuesto que esta excepcionalidad no se condecía con el número creciente de mujeres que escribían poemas o novelas, o que se desempeñaban como periodistas y presionaban por un reconocimiento laboral e intelectual en el campo cultural argentino de fines del siglo XIX (Auza, 1989; Masiello, 1994; Belluci, 1994; Johansson, 2018).

Lea Fletcher sostiene que un momento clave en el avance femenino en el asociacionismo cultural tuvo lugar en 1893 con la fundación de la Sociedad Proteccionista Intelectual por parte de la periodista y escritora María Emilia Passicot (Fletcher, 2004). De acuerdo con Héctor Lafleur, Sergio Provenzano y Fernando Alonso, esta asociación habría sido la versión femenina del Ateneo de Buenos Aires, fundado ese mismo año (Lafleur, H; Provenzano, S. y Alonso, 2006). Dando un paso más

26 BMVB, Fondo documental Cecilia Grierson CG IV 1-7.

27 En 1868 la educadora Juana Manso aceptaba una invitación para ingresar como socia honoraria, “[...] y aun invitándome a asistir a las reuniones" en la asociación Estímulo Literario, que había sido fundada un año antes en Buenos Aires. Lewkowicz (1967: 30). A su vez, Clorinda Matto de Turner fue invitada por la asociación El Ateneo de Buenos Aires a disertar en 1895. Aprovechaba esta ocasión para referirse a la cantidad de mujeres que se dedicaban a la escritura en América del sur. Lafleur, Provenzano y Alonso (2006: 38). En 1883, por su parte, la revista El Porvenir, órgano de la Sociedad Sarmiento de Tucumán, incorporaba a la joven poetisa Josefa Díaz como socia corresponsal de la localidad de Simoca, al tiempo que publicaba algunas de sus poesías. Vignoli (2015). 
en ese sentido, a fines de mayo de 1899, algunas universitarias promovieron la creación de una Biblioteca de Mujeres, que perseguía el objetivo de "protección y aliento a la mujer que se dedica a estudios superiores [...]". Se fundamentaba esa creación en la necesidad de ocuparse de "[...] los inconvenientes que encuentra [la mujer] en establecimientos de este género. Nuestro propósito se extiende además a formar una sociedad que a semejanza de otras que existen en Europa y América propenda al desenvolvimiento intelectual de la mujer, acercando elementos que hoy se encuentran aislados, favoreciendo el cambio de ideas y estimulando el trabajo". 28

Para finalizar su exposición en el Congreso Internacional, Grierson consideraba que la difusión a escala internacional de todas estas actividades era esencial, en tanto "Cuando un Consejo Nacional de mujeres se forme en mi país recién se conocerá el trabajo de nuestras mujeres y será fortificada por el apoyo moral de las concurrentes a este Congreso Internacional. Se sabrá entonces que en la Argentina la mujer es la columna de nuestra religión Nacional [sic], la vanguardia de la pureza social, de las costumbres refinadas, elegancia y felicidad doméstica, a más de su rol importante en la beneficencia”. ${ }^{29}$ Como mencionamos, al término de las sesiones fue nombrada vicepresidenta honoraria del ICW para apuntalar “[...] este movimiento de simpatía y comunicación formando el Consejo Nacional de la Mujer en Argentina". ${ }^{30}$

\section{Hacia la creación del CNMAR: composición social y primeros proyectos}

En septiembre de 1900 Grierson comenzó a enviar invitaciones para fundar el Consejo Nacional de Señoras a asociaciones "[...] de señoras o mixtas [...] que tienden al mejoramiento del hogar y á la elevación y adelanto de la mujer como factor en el progreso de la humanidad [...]. ${ }^{31}$ Además de esta convocatoria abierta hubo otra vía de reclutamiento puertas adentro decidido entre Grierson y una de las fundadoras de la Cruz Roja Argentina e integrante de la Sociedad de Beneficencia, Julia Moreno de Moreno, con el propósito de armar una comisión directiva que fijara el perfil de la institución. ${ }^{32}$ Una de las contactadas, Leonor L. de Dickinson, expresaba: “[...] he estado considerando el puesto que usted me indica, creo que es de responsabilidad y la correspondencia

28 Avalaban esta carta Elina de Correa Morales, Cecilia Grierson, María Canetti y Ernestina López. BMVB, Fondo documental Cecilia Grierson CG1 43. Debido a que esta iniciativa se da inmediatamente después de finalizado el Congreso de Londres - cuando Grierson todavía estaba en Europa- y que todas las firmantes se integraron al CNMAR una vez creado, es posible conjeturar que la Biblioteca de Mujeres fuera pensada como una asociación desde la cual integrar a las universitarias al Consejo argentino. Esta hipótesis cobra más fuerza cuando constatamos que todavía no existía la Asociación de Universitarias Argentinas.

29 BMVB, Fondo documental Cecilia Grierson. CG4, p 4-7.

30 (septiembre de 1902), Revista del Consejo nacional de la mujer en Argentina, núm. 9, p. 28.

31 BMVB, Fondo documental Cecilia Grierson CGI 49.

32 En 1900, Julia M. de Moreno escribía a Grierson: “Le pedí a mi sobrina que aceptara el cargo de prosecretaria, pues esta niña conoce el alemán como su propio idioma y es muy inteligente y activa [...] hay otra señora joven, inteligente y de una linda representación social [...] sería una espléndida secretaria, o pro". BMVB, Fondo documental Cecilia Grierson CG 1, 46. 
será mucha. Pero ya que usted y la Sra. de Moreno lo desean acepto el puesto y haré todo lo posible por cumplir mis obligaciones". Solicitaba asimismo un encuentro privado para "hablar antes de la reunión". ${ }^{33}$

Grierson intentó, además, interesar a otras mujeres universitarias, entre ellas a Petrona Eyle, quien respondía: "[...] si no concurro a la reunión preparatoria para la constitución del Consejo Nacional de Señoras no es por falta de interés [...] yo deseo que aquí entre nosotras se generalice y formalice la cuestión social de la mujer", pues "no me encuentro con mi espíritu tranquilo para ocuparme de nada más que de las tareas cotidianas de mi querida profesión [...] cuando tengan lugar las otras reuniones del Consejo iré a verla [...] a mí me gustaría tanto que se formara un club de señoras con Biblioteca, Sala de Lectura, etc. etc." ${ }^{34}$

Las expectativas para crear el Consejo eran diversas. Iban desde la incidencia directa de la beneficencia en la política social (que se manifestaría, por ejemplo, en proyectos como el de protección a la maternidad) a la obtención de información sobre asociaciones filantrópicas en el país. En este marco, las universitarias se ilusionaban con una asociación que las protegiera en sus respectivas profesiones y las estimulara en su búsqueda de mayores conocimientos. Probablemente, la base de unión de todas estas inquietudes tan disímiles fue la situación de opresión plasmada por el Código Civil de Vélez Sarsfield, pero también el anhelo de entrar en contacto con los problemas femeninos y feministas del mundo, la fascinación por Europa y por las norteamericanas, y una curiosidad genuina por descubrir la manera en la que sociedades tan distantes y exóticas pensaban y resolvían la cuestión de las mujeres. Lo que descubrirían es que con esta integración, ese mundo de mujeres no sólo estaba cerca sino que también miraba a la Argentina y comenzaba a interesarse por ellas. ${ }^{35}$

El 25 de septiembre de 1900 se creó formalmente el Consejo y se eligió la primera comisión directiva que intentó expresar el mosaico de inquietudes que convivían en la asociación, donde la beneficencia y los contactos políticos tenían preponderancia. ${ }^{36}$ Una vez establecida, sus integrantes debieron salir rápidamente a aclarar

33 BMVB, Fondo documental Cecilia Grierson CG 1, 47. Leonor L. de Dickinson era delegada de la Sociedad International Home, que presidía Jean Thomson Raynes, y a la que hicimos ya referencia.

34 BMVB, Fondo documental Cecilia Grierson CG 1, 48. Desde abril de 1902 la Asociación de universitarias argentinas tendría a María Canetti como delegada provisional "hasta tanto se reúnan los miembros de la asociación y se determine quién les representará definitivamente". (junio de 1902) Revista del Consejo nacional de la mujer en Argentina, nro. 6, p. 22. Sin embargo, la incorporación de las universitarias al CNMAR se formaliza tres años después cuando presentan sus estatutos. (junio de 1905), Revista del Consejo nacional de la mujer en Argentina, nro. 18, pp. 32-33.

35 Las cursivas nos pertenecen.

36 La primera comisión directiva estuvo integrada por: Albina Van Praet de Sala, Presidenta; Carolina García Lagos, Vice-presidenta; Cecilia Grierson, Vice-presidenta segunda; Julia Moreno de Moreno, Tesorera; María de Guerrico, Secretaria de actas; Ana Brinckmann de Wasserman, Pro-Secretaria de actas; Isabel Lynch de Du Sartel, Secretaria de correspondencia del interior; Celina Barraza, Pro- Secretaria de correspondencia del interior; Jean Thomson Raynes, Secretaria de correspondencia del exterior. Como ya mencionamos, Albina de Sala había sido presidenta de la Sociedad de Beneficencia; Carolina García Lagos también había ocupado ese importante cargo, pero además era la esposa del ex presidente Carlos Pellegrini (1890-1892); Cecilia Grierson como vimos, había sido la primera médica argentina, mientras que Julia Moreno de Moreno, había actuado en la Sociedad de Beneficencia de la capital y fue una de las fundadoras de la Cruz Roja. Tenían 46, 48, 41 y 39 años, respectivamente, al momento de crear el Consejo. El resto de la comisión directiva ocupaba cargos importantes en asociaciones de beneficencia y caridad (Sosa de Newton 1986). 
cuál era la posición del Consejo respecto del feminismo. Más tarde Grierson lo explicaría del siguiente modo:

Cuanto tiempo perdido en intentar explicar, traducir y convencer! La prensa escéptica, aunque de buena voluntad, no estaba al cabo del verdadero significado de este movimiento, confundiéndolo con el de las sufragistas, llamándolo emancipista y creyendo que la palabra feminismo era solo alguna de las dos tendencias anteriormente mencionadas, o las dos a la vez. No comprendiendo que el verdadero movimiento feminista conservador es el que busca el adelanto de la mujer sin embarcarse en exageraciones y errores. ${ }^{37}$

También quedó claro que el propósito en esta primera etapa era el diálogo con la comunidad internacional. Para cumplir este objetivo, la "Secretaría de Correspondencia con el Exterior” fue un lugar clave que debía estar ocupado por una persona con un capital cultural de alto nivel, en el que las competencias idiomáticas eran imprescindibles. La lectura de las noticias internacionales comenzó a ganar cada vez más importancia en las reuniones de la asociación. Esto lo hizo notar Dolores Lavalle de Lavalle, quien presentó una moción para alterar las lecturas en las reuniones porque "[...] muchas asistentes, por vivir en el campo o por otras razones, tienen que retirarse antes de concluida la sesión, lo que las priva de escuchar las partes de mayor interés, como ser los informes de sociedades o comunicaciones del extranjero" ${ }^{38}$

La Secretaría de Correspondencia del Exterior no sería el único canal de diálogo con la comunidad internacional. En efecto, en la primera reunión, Grierson presentó exitosamente dos propuestas interrelacionadas. Primero, la creación de una Secretaría de Prensa y Propaganda, "compuesta de personas que dirigen o escriben en periódicos"; ${ }^{39}$ complementando esta secretaría, la edición de una revista. Con algunas pequeñas modificaciones, el staff de esta sección fue el que propuso Grierson..$^{40}$ La publicación, por su parte, estuvo a cargo de mujeres vinculadas a las Letras y al magisterio y de alguna de las primeras universitarias. Si bien este ámbito estuvo presidido por Freyre de Jaimes, muy cercana a la presidenta de la asociación, el grupo de universitarias fue cobrando cada vez más importancia. En efecto, allí se destacaron particularmente Ernestina y Elvira López como editoras de la revista mencionada. Las hermanas López contaron con la libertad suficiente para mostrar sus habilidades, obtenidas en su paso por la enseñanza superior -en particular la publicación de ensayos filosóficos de su autoría-, pero también se destacaron como editoras, ejerciendo el control de la publicación y decidiendo sobre sus contenidos. No era un rol menor, sobre todo si tenemos en cuenta que la publicación circulaba por todo el país y que era el órgano de promoción del Consejo en el exterior. De hecho la revista llegó a ser

37 (diciembre de 1902), Revista del Consejo nacional de la mujer en Argentina, núm. 8, p. 7.

38 (junio de 1902), Revista del Consejo nacional de la mujer en Argentina, núm. 6, p. 11.

39 (julio de 1901), Revista del Consejo nacional de la mujer en Argentina, núm. 2, p. 7.

40 La presidenta fue Carolina Freyre de Jaimes, a la que acompañaban Elvira y Ernestina López, Celestina Funes de Frutos, Georgina M. Gibbins, Mercedes Pujato Crespo, Yole Zolezzi de Bermúdez, Clorinda Matto de Turner, Pascuala Cuetto, Catalina A. de Bourel, Ana Pintos, Elia M. Martínez, Eusebia de Rojas, Miss Isabel King y Laura Ratto. 
muy elogiada por la presidenta del ICW, May Sewall, quien consideró que “[...] está tan arreglada y editada que pensamos que bien vale la pena aprender el español con el solo objeto de conocer las interesantes informaciones de nuestro único consejo en Sud América". ${ }^{41}$

En cuanto a la dinámica interna del Consejo, es importante mencionar que eran las asociaciones (y no las personas individualmente) las que integraban los miembros del CNMAR, aunque por supuesto la representación de una asociación recaía en una persona, que era la que en definitiva tomaba decisiones. Con el tiempo, se creó la figura de socia honoraria. A pesar de esto, la votación destinada a la renovación de la comisión directiva o a la presentación de mociones se realizaba a través de las asociaciones, correspondiéndole un voto a cada una. Por ejemplo, Grierson participó en el Consejo como presidenta de la Asociación de Enfermeras y Masajistas (fue desde esa pertenencia asociativa que mocionó para la creación de la sección de economía doméstica, por ejemplo) y no como parte de la Asociación de Universitarias argentinas.

Volviendo a los orígenes del CNMAR, varias asociaciones de San Luis, Corrientes, San Juan, Jujuy, Capital Federal, Azul, Tandil y La Plata respondieron al llamado para fundar el Consejo. De las veintisiete asociaciones presentes en la primera reunión, solamente cuatro -la Sociedad Internacional Kindergarten (cuya presienta era Sarah Eccleston, una de las maestras norteamericanas que continuó residiendo en el país), la Asociación de Enfermeras y Masajistas (cuya fundadora y presidenta era Grierson), la Escuela Normal de Mujeres de Concepción del Uruguay (representada por Isabel King) y la Sociedad Santa Marta ${ }^{42}$ (cuya presidenta era Dolores Lavalle de Lavalle)- no sólo tenían propósitos benéficos, caritativos o religiosos. ${ }^{43}$

En este marco, es interesante hacer notar que el ingreso de otras asociaciones que desentonaban con este perfil, como la Asociación de Universitarias Argentinas y la Asociación de Protección Mutua a la Mujer Intelectual, cuyas presidentas eran Petrona Eyle y Catalina de Bouruel, respectivamente, se dio bastante más tarde, en abril de 1902. Además, en ambos casos se aclaró que se trataba de un ingreso provisorio. Como vimos, las universitarias formalizarían su situación en

41 (abril de 1902), Revista del Consejo nacional de la mujer en Argentina, núm. 7, p. 19.

42 La Sociedad Santa Marta, fundada en 1895, había surgido con el propósito de otorgar a las mujeres jóvenes de escasos recursos una educación “[...] más práctica que la que reciben en las escuelas del Estado". Su fundadora, Dolores Lavalle de Lavalle, se había inspirado en escuelas profesionales de Europa y Estados Unidos, donde existían, anexas, escuelas profesionales a cada institución educativa. Se proyectaba como una sociedad que fundaría varias escuelas de este tipo. El programa de estudios se componía de dos cursos: por una parte, el general obligatorio (incluía nociones generales y cocina, servicio doméstico y costura); por otro, el especial, destinado a aquellas que quisieran seguir una profesión. Este incluía talleres sobre cocina, lavado, planchado, confección de vestidos de señoras y niños, costura y bordado en blanco, corsetería, zurcido, peinados, confección de sombreros y trabajo relativo a las mucamas. Se calculaba que alrededor de 150 alumnas concurrirían mensualmente a la escuela. Los recursos con los que dicha escuela contaría, al ser gratuita, provendrían en gran parte del Ministerio de Educación, que proporcionaría las maestras así como el mobiliario necesario.

43 Con algunas variaciones, esta tendencia se mantuvo a lo largo del período, aunque la brecha se fue acortando. En 1904, de las 61 asociaciones incorporadas, 46 eran benéficas o religiosas, mientras que 15 respondían a otros intereses. Si consideramos el año 1907, de las 62 asociaciones adheridas, solamente 18 eran de índole cultural, educativa o intelectual. 
el Consejo recién en 1905, cuando presentaron sus estatutos. En ellos se mencionaban los propósitos, entre los que se contaban "dar un aplauso cada vez que una mujer realice un acto intelectual importante [...] así como prestar apoyo moral, cuando los intereses de alguna mujer se hallen lesionados, ó sean desconocidos sus derechos". ${ }^{44}$ De modo que las universitarias que actuaron en el Consejo previamente, lo hicieron bajo otra pertenencia asociativa o bien de manera provisoria.

La primacía de la beneficencia también se manifestó en el lugar de reunión del Consejo. Si bien Grierson informaba que las gestiones realizadas por Eusebia Silveyra de Rojas (Directora de la Escuela Comercial de Mujeres) ante el Ministro de Educación Osvaldo Magnasco habían dado resultado y por lo tanto se había obtenido la posibilidad de utilizar la Escuela Comercial de Mujeres para las reuniones, éstas terminaron realizándose en los salones de la Sociedad Rural, ofrecida a Albina de Sala por su presidente, Ezequiel Ramos Mexía, también Ministro de Obras públicas y Agricultura. Además del lugar oficial de reunión, en ocasiones, una comisión más reducida se reunía en la casa de la presidenta. Las sub-comisiones se juntaban, por su parte, en otros espacios. Así, la de Prensa y Propaganda ocupó durante largo tiempo las oficinas de la revista La columna del hogar.

La composición social también se expresó en las diversas inquietudes de las socias una vez conseguida la personería jurídica y, con ella, la posibilidad de presentar proyectos. En efecto, la obtención de personería jurídica por parte del CNMAR en agosto de 1902 fue celebrada por todas las socias como un triunfo que les permitiría demostrar toda su influencia. En realidad era mucho más que eso. En términos generales, significaría para estas mujeres, que tenían menoscabados sus derechos en el contexto de la vigencia del Código Civil de Vélez Sarsfield, estar en condiciones, por el contrario, de presionar y convertirse en un actor más que disputaba derechos vinculados a su condición femenina. ${ }^{45}$

A través de la presentación de proyectos se irían moldeando de un modo más nítido los intereses de cada grupo y las pujas internas por poner en agenda sus inquietudes. Es lo que ocurrió al exponerse tres proyectos en una misma reunión: "Protección a la maternidad”, "Protección al niño obrero" y "Enseñanza de economía doméstica”. El 25 de septiembre de 1902, tan solo un mes después de obtenerse la personería jurídica, se informaba que el proyecto relativo a la maternidad (promovido por Albina de Sala y María Guerrico) había sido presentado al Congreso de la Nación. Cabe mencionar que en dicha reunión, además de las socias presentes, se encontraban Patricio Sala (marido de Albina) y Marco M. Avellaneda (Ministro de Hacienda), entre otros. En el encuentro, la presidenta comenzó explicando los argumentos que lo habían generado: "Nos ha preocupado la situación mísera y

44 (junio de 1905), Revista del Consejo nacional de la mujer en Argentina, núm. 18, p. 33.

45 El nacimiento de la "cuestión social" como problema que requería la atención de los poderes públicos, fue acompañado de esfuerzos realizados para describir y explicar sus múltiples aristas. En este sentido, la tesis de la segunda médica argentina, Elvira Rawson de Dellepiane, titulada "La higiene de la mujer", defendida en 1892, constituyó un esfuerzo más por evidenciar y también modificar la situación de desprotección y peligro en el que se encontraban las mujeres pobres que no contaban con recursos ni información para ocuparse de los cuidados y de su propia salud. Cabe aclarar que luego de unos años, en 1904, Rawson sería invitada a integrar el CNMAR. Para un análisis del surgimiento de la cuestión social en Tucumán, ver Campi y Vignoli (2016). 
desamparada de la mujer obrera y artesana que está próxima a ser madre. Basta recorrer las fábricas y talleres de mil industrias [...] para sentir que la piedad, la misericordia y el altruismo nos muevan a meditar consuelo a tanta desgracia". Describía el estado en el que se encontraban estas mujeres y lo perjudicial de la situación tanto para ellas como para "generaciones de ciudadanos que constituyen la eternidad de una Nación”. ${ }^{46}$ Proponía el cuidado de la madre antes, durante y después del nacimiento por medio de una reducción del porcentaje que pagaba la Lotería Nacional a los vendedores de billetes. El Consejo Nacional de Mujeres administraría este dinero, con el que se encargaría de socorrer a estas mujeres.

A continuación, Elvira López hizo uso de la palabra y se refirió a otro proyecto recientemente presentado por Miguel Cané y Lidoro J. Avellaneda, que se ocupaba de la protección al niño obrero. ${ }^{47}$ Argumentaba en favor del mismo que "[...] había sido ya presentado por la actual presidenta de la sub comisión de prensa en su segundo informe y consideraba que al consejo le correspondía la prioridad de la idea, porque lo pensaba como un corolario del de protección a la maternidad". Sin embargo, la presidenta contestó que era imposible acumular proyectos y que "[...] se debía ir haciendo las cosas por orden. Se podía descansar en la seguridad que el Consejo se ocuparía siempre con preferencia de aquellos que entrañaran un bien para la humanidad, ya sea en favor de la mujer o del niño. ${ }^{48}$

Pero en esa misma reunión se expuso un tercer proyecto. No era otro que el de Grierson, quien a través de la Asociación de Enfermeras y Masajistas proponía la creación de una Sociedad de Educación Doméstica. Para informar a las socias de qué se trataba, compartió información sobre educación técnica de la mujer en Europa y Estados Unidos, donde se definía a la economía doméstica como el progreso e higienización de las casas, la alimentación y el bienestar de toda la familia. Situaba el surgimiento de la ciencia doméstica hacia 1885 en Alemania y en torno de los conocimientos de cocina impartidos a las mujeres. Pero lo hacía extensivo a todo el movimiento del hogar: "[...] es necesario que la economía reine en cada casa, que en todas haya conocimiento del valor del dinero y su división; del tiempo, fuerza y trabajo; conocimiento de los materiales crudos y del producto completo del alimento; de los utensilios y de las ropas; y un plan trazado cuidadosamente sobre su manejo y orden [...]”. Argumentó al respecto que el objetivo del Consejo era el perfeccionamiento del hogar y la elevación y el adelanto verdaderos de la mujer, pero también planteó una crítica a la educación femenina en la Argentina: "En este país en que se enseña la costura como única industria y el magisterio como única profesión, es necesario subsanar estas deficiencias, abriendo otros campos al trabajo de la mujer y enseñándoles al mismo tiempo los conocimientos del hogar". 49

46 (diciembre de 1902), Revista del Consejo nacional de la mujer en Argentina, núm. 8, p. 9.

47 En 1902, los senadores nacionales Miguel Cané y Lidoro J. Avellaneda, haciéndose eco de insistentes pedidos (como el del Patronato de la Infancia por ejemplo), presentaron un proyecto de ley sobre admisión del niño en la industria. Recién regresado de Europa, Cané mencionó especialmente las leyes francesas promulgadas en el transcurso de 1892 y 1894, que habían servido de modelo para la confección del proyecto que Jorge Williams presentara en 1899 al Patronato de la Infancia (Aspell, 2000).

48 (diciembre de 1902), Revista del Consejo nacional de la mujer en Argentina, núm. 8, p. 11.

49 (marzo de 1903), Revista del Consejo nacional de la mujer en Argentina, núm. 9, p. 29. 
En noviembre de 1902, se constituyó la Sub-comisión de Economía Doméstica dentro del CNMAR y a fines de 1903 sus integrantes se dirigieron al Ministro de Justicia e Instrucción Pública para proponerle que todas las escuelas normales de la Capital Federal tuvieran el deber de agregar un curso de Enseñanza Técnica del Hogar con el propósito de incorporar nociones de lavado, planchado y cocina. A pesar de la respuesta negativa, Grierson siguió adelante y se redactaron los estatutos de la citada subcomisión. Entre los propósitos se encontraban fomentar la enseñanza práctica en los asilos y escuelas y establecer cursos y escuelas relativas al hogar en todos los centros de educación, sociedades y asilos. También, la creación para niñas y adultas, en las ciudades y en la campaña, de centros de educación técnica industrial, la vinculación con otros dedicados a la educación agrícola y el fomento de la fundación de museos y bibliotecas especiales, así como de espacios para la práctica de las artes domésticas e industriales destinados a la enseñanza en torno al hogar y la industria. El cuarto capítulo se refería a los medios de progreso y estímulo. Por ejemplo, la subcomisión impartiría o realizaría conferencias, clases, lecturas, visitas, excursiones, pero también mantendría correspondencia dentro y fuera del país para la mejora de la economía doméstica, intentando conseguir revistas y periódicos sobre la temática. Se disponía, además, a ofrecer protección a las alumnas que frecuentaran los cursos, pero también un patronato dirigido a las que egresaran. En cuanto a las autoridades de la subcomisión, éstas se elegirían de manera secreta, se someterían al reglamento del CNMAR y se comprometerían a informar una vez por año el estado de su caja y sus actividades en reuniones del Consejo. La subcomisión comenzó a funcionar en junio de 1903 y recién un año después se dictaría la primera clase.

La creación de esta subcomisión y la implantación de la educación mencionada en el país se reforzaron en 1904, durante la visita de las hermanas Ernestina y Elvira López a Estados Unidos, donde participaron en la Exposición Universal de San Luis y en la reunión del Consejo Internacional de Mujeres. Este viaje impactó profundamente en las hermanas López, quienes se ocuparon de realizar una crónica casi diaria de la experiencia. En una de las cartas enviadas a Grierson señalaban:

\begin{abstract}
Quisiera hablarle de la exposición. Al palacio de educación me lo conozco como a mis manos, pues Ernestina asistió diariamente a él y yo con ella. Contiene una exposición muy completa de los sistemas escolares de todo el mundo. Norteamérica y Alemania se llevan la palma mientras que Cuba y Japón despiertan interés. En la sección de San Luis hubo clases públicas de las diferentes materias y una vez por semana clases de cocina". Junto con las hermanas López también viajó Sarah Eccleston, quien expuso en nombre del CNMAR en la reunión internacional: "Hablé de los progresos de economía doméstica, de la biblioteca y de los trabajos hechos pro paz uruguaya, por la protección a la maternidad y el pedido de ingresar a las cárceles para ayudar.
\end{abstract}

La subcomisión de Economía Doméstica continuó ganando importancia. En 1905 se inauguró la Escuela Técnica del Hogar en un local cedido por la Municipalidad. En esa oportunidad, el Director del Consejo Nacional de Educación había asistido 
al evento, y por lo tanto sus integrantes aprovechaban para comentar que además de los cursos de corte y confección y de cocina se había establecido un curso de modistería y se proyectaba otro de planchado artístico. La economía doméstica tuvo tanto éxito en la asociación que en ese mismo año se crearía otra escuela en La Plata, dirigida por Virginia Moreno. Además, se informaba que Enrique Carbó, gobernador de Entre Ríos, había decidido implementar la enseñanza de la economía doméstica en su provincia, por lo que había enviado a varias maestras a interiorizarse sobre su funcionamiento en la Capital Federal. En abril de 1906, Grierson señalaba que había sido requerida desde Uruguay para instalar una institución relativa a economía doméstica en el vecino país.

El proyecto de economía doméstica que Cecilia Grierson llevó adelante durante varios años dentro del CNMAR, y que se convirtió en su misión más importante en la Asociación, no sólo no colisionaba con los intereses del grupo de socias que provenía de ámbitos de beneficencia y caridad, sino que se complementaba armoniosamente con proyectos en los que algunas damas venían trabajando, como es el caso de la Asociación Santa Marta a la que ya hicimos referencia y que presidía Dolores Lavalle de Lavalle. Probablemente en estos puntos en común estén los fundamentos de una alianza que ha sido incómoda de explicar para parte de la historiografía argentina.

\section{Consideraciones finales}

En este trabajo nos interrogamos por los antecedentes del Consejo Nacional de la Mujer surgido en Argentina, partiendo de considerar la trayectoria y los intereses profesionales de una de sus fundadoras, la médica Cecilia Grierson, quien entabló una singular y duradera relación con algunas mujeres pertenecientes a la Sociedad de Beneficencia de la Capital Federal, el otro grupo fundador del Consejo argentino. Nos interesó explicar los motivos de esta alianza, forjada veinte años antes de la creación de la asociación y vigente luego durante una década más. En efecto, como primera egresada de la carrera de medicina de la Argentina, Grierson necesitó contactos y vínculos estrechos con aquellas mujeres que participaban en asociaciones que tenían injerencia en el sistema sanitario argentino y que, por lo tanto, podían interceder para la obtención de cargos en hospitales situados bajo su órbita; o mediar ante eventuales conflictos, siempre latentes en un ambiente caracterizado por la inferioridad jurídica de las mujeres. Por otra parte, y a pesar de su omnipotencia y despliegue territorial, la Sociedad de Beneficencia también necesitaba de Grierson y del grupo de universitarias que la siguieron en la creación del Consejo.

En un momento carente de grandes posibilidades de maniobra frente a los múltiples abusos que encontraban fundamento en el texto de Vélez Sarsfield, entablar una relación con aquellas mujeres que estaban logrando entrar en ambientes absolutamente masculinos (tal el caso de las universidades, bibliotecas o asociaciones culturales) significaba una experiencia de la que podían aprender y sacar 
provecho. De modo que en los años inmediatamente anteriores a la formación del CNMAR, hubo admiración, una corriente de respeto y elogios mutuos entre ambos grupos. Es por este motivo que en el momento de crearlo tanto Grierson como las damas de la beneficencia oficial, consideraron necesaria y hasta "natural" esta alianza.

No es un dato menor que cuando fundan el Consejo sus figuras más relevantes, -Albina Van Praet de Sala, Cecilia Grierson, Dolores Lavalle de Lavalle, Carolina García Lagos y Julia Moreno de Moreno- tenían entre 39 y 69 años y contaban con una vasta experiencia en el asociacionismo femenino de diverso tipo, que en algunos casos se remontaba a 20 años atrás. Estas mujeres volcaron toda esa trayectoria junto al capital político, económico e intelectual acumulado durante ese tiempo en este nuevo proyecto que comenzaba a navegar hacia 1900.

Sin embargo, gran parte de la historiografía que se interesó por el feminismo en el Cono Sur la consideró inviable desde sus orígenes porque en su "ADN" ya estaban los conflictos que sobrevendrían casi una década después. La ausencia de explicación sobre las razones de esa alianza inviable generó una serie de equívocos que van desde la idealización de la figura de Grierson, entendiendo que habría asumido el ideario feminista incluso antes de crear el Consejo, hasta la simplificación del propio feminismo, como si éste hubiera emergido sin variantes ni matices en la Argentina de principios de siglo XX; ausencia que impide comprender por qué las mujeres de la beneficencia se interesaron por el proyecto. A nuestro juicio, ese interés no habría sido posible en caso de haber estado éste signado por una fervorosa adhesión a causas que ellas consideraban "extravagantes" e "irrealizables" en el país. En este sentido, consideramos que trasladar la escisión de 1910 a 1900 obtura la posibilidad de entender los motivos por los cuales grupos de características diferentes convergieron en torno a una idea y convivieron armónicamente al menos durante ocho años.

Entendemos, según lo señalado, que en estudios precedentes tuvo lugar una idealización, al considerar que Grierson y el pequeño grupo de mujeres que la siguieron en la creación del Consejo, es decir universitarias de clase media alta vinculadas al mundo del saber, habrían abrazado sin dudar la causa feminista en 1900, incluyendo la lucha por el sufragio femenino. Si hubiera sido así, otras universitarias, animadas por ideas más en sintonía con un feminismo radical, hubiesen adherido al Consejo; no lo hubieran abandonado prontamente, como lo hicieron Julieta Lanteri, Elvira Rawson de Dellepiane y Petrona Eyle, por nombrar algunas desencantadas, como lo explicitaron en alguna reunión. Pero además, hubo otra línea que abrazó un feminismo radical que ni siquiera se acercó al Consejo: María Abella Ramírez y el grupo de mujeres que publicó Nosotras, la primera revista feminista de la Argentina, fundada en 1902.

Creemos que durante los primeros años, la heterogénea membresía estuvo interesada en otros proyectos que consideraba más importantes o más urgentes que la discusión sobre las posibilidades del feminismo en la Argentina. Es por esto que, más que las universitarias, que presionaron para dar lugar a un debate serio 
sobre el feminismo dentro del Consejo, fue la comunidad internacional a la que estaban vinculadas la que intentó instalar algunas discusiones al respecto. La lectura de las noticias internacionales, que prolijamente tenía lugar al comenzar cada reunión desde que Dolores Lavalle de Lavalle lo propusiera, traía novedades sobre experiencias relativas al voto femenino en el mundo y sobre el pedido de opinión respecto a cuestiones políticas; también invitaciones a participar en reuniones como la de la Alianza Universal por el Sufragio Femenino o para impulsar encuestas sobre la situación jurídica y económica de las mujeres en la Argentina. Fue principalmente al calor de esas lecturas que surgieron tímidos debates sobre los feminismos que se plantearon en el CNMAR durante sus primeros años de existencia. 


\section{Bibliografía}

" Aspell, M. (2000). La cuestión social en el último cuarto del siglo XIX: los proyectos presentados a las cámaras del Congreso Nacional". Anuario CIJS, 4, pp. 201-211.

"Auza, N. (1989). Periodismo y feminismo en la Argentina 1830 - 1930. Buenos Aires: Emecé.

" Barrancos, D. (2002). Inclusión/Exclusión. Historia con mujeres. Buenos Aires: Fondo de Cultura Económica.

"Barrancos, D. (2005). Primera recepción del término "feminismo" en la Argentina. Labrys, 8. Consultado en línea en:

" http://www.memoria.fahce.unlp.edu.ar/art_revistas/pr.11393/pr.11393.pdf, 20/11/2019.

" Barrancos, D. (2014a). Participación política y luchas por el sufragio femenino en Argentina (1900-1947). Cuadernos Inter.c.a.mbio sobre Centroamérica y el Caribe. Vol. 11, (1), pp. 15-26.

" Barrancos, D. (2014b). "Los caminos del feminismo en la Argentina. Historia y derivas". Voces en el Fénix, 32, pp. 7-13.

"Belluci, M. (1994). De la pluma a la imprenta. En Fletcher, L. (comp) Mujeres y cultura en la Argentina del siglo XIX. Buenos Aires: Feminaria.

" Bianchi, S (1986). Peronismo y sufragio femenino: la ley electoral de 1947. Anuario IEHS, 1, pp. 255-296.

" Binda, M., Silveira, R. y Krämer, C. (2012). Cecilia Grierson, la primera médica argentina. Revista Argentina de Radiología, 74 (4), pp. 361-365.

" Botana, N. y E. Gallo. (1997). De la República posible a la República verdadera (18801910). Buenos Aires: Ariel.

" Boussahba-Bavard M. y R. Rogers (2017). Women in International and Universal Exhibitions, 1876-1937. Londres: Routledge.

" Campi, D y M. Vignoli (2016). La emergencia de la cuestión social en Tucumán. Un concurso de la Sociedad Sarmiento de 1892, Nuevo Mundo. Mundos Nuevos. Consultado en: http://journals.openedition.org/nuevomundo/69361. Fecha: 12/02/2020.

" Carlson, M. (1988). Feminismo! The Women Movements in Argentina from its beginnings to Eva Perón. Chicago: Academy Chicago.

"Ciafardo, E. (1990). Las damas de beneficencia y la participación social de la mujer en la ciudad de Buenos Aires, 1880-1920. Anuario del IEHS, 5, pp. 161-170.

"Correa Luna, C. (1925). Historia de la Sociedad de Beneficencia, T. 2. Buenos Aires: Talleres gráficos del asilo de huérfanos.

" Cova, A. (2014). The national councils of women in France, Italy and Portugal: comparisons and entanglements, 1888-1939. En Janz, O and D. Shonpflug. Gender history in a transnational perspective, biographies, networks and gender orders. Londres: Berghan.

"Crespo, J. (2007). Las maestras de Sarmiento. Buenos Aires: Grupo Abierto Comunicaciones.

" Cuadro Cawen, I. (2018). Feminismos y política en el uruguay del novecientos. Uruguay: Ediciones de la Banda Oriental. 
"De Asúa, M. (2011). La fiesta de la ciencia. Academia Nacional de Ciencias de Buenos Aires, 21 (125), pp. 18-24.

"De Paz Trueba, Y. (2010). Mujeres y esfera pública: la campaña bonaerense entre 1880 y 1910. Rosario: Prohistoria.

" Ehrick, C. (1998). Madrinas and Missionaries: Uruguay and the Pan-American women's movement, Gender and History, 10 (3), pp. 406-424.

" Fletcher, L. (2004). La profesionalización de la escritora y de sus protagonistas. Argentina, 1900-1919. Revista Iberoamericana, Pennsylvania, 70 (206), pp. 213-224.

" Girbal-Blacha, N. (2006). Nacimos para construir hogares. No para la calle. La mujer en la Argentina peronista (1946-1955). Continuidades y cambios. Secuencia, 65, pp. 93-104.

" Gluzman, G. (2013). El trabajo recompensado: mujeres, artes y movimientos femeninos en la Buenos Aires de entresiglos. Artelogie, 5, pp. 1-22.

" Grierson, C. (1910). Decadencia del Consejo Nacional de la Mujer Argentina. Buenos Aires.

" Guy, D. (2011). Las mujeres y la construcción del Estado de Bienestar. Caridad y creación de derechos en Argentina. Buenos Aires: Prometeo.

" Hammon, G. (2004). Women can vote now: feminism and the women's suffrage movement in Argentina, 1900-1955. PH. D. Dissertation, University of Texas.

" International Council of Women (1966). Women in a changing world: The dynamic story of the International Council of Women since 1888. London: Routledge.

" Johansson, L., Efecto Mariposa en la prensa tucumana: mujeres redactoras en 1870. En Vignoli, M. y L. Reyes de Deu (2018). Género, cultura y sociabilidad en el espacio rioplatense, 1860-1930. Rosario: Prohistoria.

"Kapeli, A. (2000). Escenarios del feminismo. En Duby, G. y M, Perrot. Historia de las mujeres. El siglo XIX, Cuerpo, trabajo y modernidad, T. VIII, Barcelona: Taurus.

" Lavrín, A. (1997). Cambiando actitudes sobre el rol de la mujer: experiencia en los países del Cono sur a principios de siglo. European review of Latin American and Caribbean studies,62, pp. 71-92.

"Lobato, M. (2010). Conmemoraciones patrióticas y mujeres: los desafíos del presente en el bicentenario de la Revolución de Mayo, Mora, 16, pp. 162-165.

" Loncarica, A. (1976). Cecilia Grierson: vida y obra de la primera médica argentina. Buenos Aires: Editorial Stilcograf.

"López, E. (2009). El movimiento feminista. Primeros pasos del feminismo en Argentina. Buenos Aires: Biblioteca Nacional.

" Marino, K. (2019). Feminism for the Americas: the Making of an International Human Rights Movement, North Carolina: University of North Carolina Press.

" Martin, A. L. (2020). Trayectorias que se cruzan. Cecilia Grierson y María Elena Ramos Mejía. En Ramaciotti, K. (Dir.) Historias de la enfermería en la Argentina. Pasado y presente de una profesión. Buenos Aires: Edunpaz.

" Martínez Prado, N. (2015). La emergencia del feminismo en la Argentina:un análisis de las tramas discursivas a comienzos del siglo XX. Revista Estudos Feministas, 23 (1), 71-97.

" Masiello, F. (1994). La mujer y el espacio público: El periodismo femenino en la Argentina del siglo XIX, Buenos Aires: Feminaria.

" Mollés, D. (2013). Transferencias y luchas culturales transatlánticas: feminismo, librepensamiento y redes masónicas entre Europa y América (1860 - 1910). Rehmlac, Vol. 4, pp 90- 112. 
"Moreno, J. (2009). Éramos tan pobres...de la caridad colonial a la Fundación Eva Perón. Buenos Aires: Sudamericana.

" Morrone, B. (2016). Cecilia Grierson: la transdisciplinariedad como oportunidad. Estudio de la producción militante intelectual de Cecilia Grierson respecto del debate de la modernidad socio-sanitaria en la Argentina contemporánea, tesis doctoral, 2016. Consultado en línea en http://sedici.unlp.edu.ar/handle/10915/55150 10/02/2020).

" Moynagh, M y N. Forrester (Eds.) (2000). Documenting First Wave Feminisms: Transnational Collaborations and Crosscurrents, Vol. 1, Toronto: University of Toronto Press.

"Nari, M. (2004). Políticas de maternidad y maternalismo politico. Buenos Aires: Biblos.

" Offen, K. (2014). “Understanding international feminism as 'Transnationalism' - an anachronism? May Wright Sewall and the creation of the International Council of Women, 1889-1904. En Janz, O and D. Shonpflug. Gender histooy in a transnational perspective, biographies, networks and gender orders. London: Berghan.

" Parra, G. (2001). Antimodernidad y trabajo social. Orígenes y expansión del trabajo social argentino. Buenos Aires: Espacio Editorial.

"Pérgola, F. (2015). Cecilia Grierson, primera médica argentina. Revista Argentina Salud Pública, 6 (24), pp. 47-48.

"Pita, V. (2012). La casa de las locas. Una historia social del Hospital de Mujeres Dementes, Buenos Aires, 1852-1890. Rosario: Prohistoria.

"Queirolo, G. (2018). Mujeres en las oficinas. Trabajo, género y clase en el sector administrativo (Buenos Aires, 1910 - 1950). Buenos Aires: Biblos.

" Ramos, L. (2021). Las señoritas. Historia de las maestras estadounidenses que Sarmiento trajo a la Argentina en siglo XIX. Buenos Aires: Lumen.

" Recalde, H. (2010). Señoras, universitarias y mujeres (1910-2010) La cuestión femenina entre el centenario y el bicentenario de la Revolución de Mayo. Buenos Aires: Grupo Editor Universitario.

" Revista del Consejo nacional de la mujer en Argentina, BNMM, Biblioteca Nacional Mariano Moreno, Buenos Aires, números 2-38.

" Rupp, L. (1997). World of Women. The Making of an International Women's Movement. New Jersey: Princeton University Press.

"Sandell, M. (2015): The rise of women's transnational activism: Identity and sisterhood between the world wars. New York: Tauris.

"Sinha, M. Donna J. Guy y Woollacott, Angela (1998). Why feminism and Internationalism? Gender and History, 10 (3), pp. 345-357.

"Sosa de Newton, L. (1986) Diccionario biográfico de mujeres argentinas. Buenos Aires: Plus ultra.

" Universitarias Argentinas. (1911). Primer Congreso Femenino Internacional de la República Argentina, Buenos Aires: Ceppi.

"Valobra, A. (2008). Feminismo, sufragismo y mujeres en los partidos políticos en la Argentina de la primera mitad del siglo XX. Amnis. Revue de civilisation contemporaine Europes/Amériques (8). En Memoria Académica. Consultado en http://www.memoria. fahce.unlp.edu.ar/art_revistas/pr.7382/pr.7382.pdf, 3/11/2020.

"Vasallo, A. (2000). Entre el conflicto y la negociación. Los feminismos argentinos en los inicios del Consejo Nacional de Mujeres, 1900-1910, en Gil Lozano, F. et al, Historia delas mujeres en la Argentina Siglo XX. T. II. Buenos Aires: Taurus. 
"Vasallo, J. (2012). Señoras patriotas ¿̇o reacción oligárquica? Actas del Primer Congreso Patriótico de Señoras en América del Sud, 1910. Córdoba: Universidad Nacional de Córdoba.

"Vignoli, M. (2018). El Consejo Nacional de la Mujer en Argentina y su dimensión internacional, 1900-1910. Revista Travesía, Vol. 20 (2), pp. 121-147.

"Vignoli, M. (2019a). Elvira Rawson de Dellepiane y la "Comisión Pro derechos de la mujer": Proyección nacional del feminismo argentino durante la década del 20, XIV Jornadas nacionales de historia de las mujeres, IX Congreso Iberoamericano de estudios de género, Mar del Plata, inédito.

\section{Repositorios documentales}

"Biblioteca Nacional Mariano Moreno, Buenos Aires.

" Fondo Cecilia Grierson, BMVB, Biblioteca Max Von Buch, Buenos Aires. 